\title{
DNA-chip firm backs down over upgrade
}

John Whitfield, London

Biotechnology company Affymetrix is retreating from a plan that would have made it tougher for biologists to use opensource computer software to analyse results from its ubiquitous microarray chips.

The firm, based in Santa Clara, California, had planned to upgrade its microarrays, which are used by thousands of molecular biologists to detect gene activity. It hoped that the upgrade would have made the output files from its chips smaller and faster to process.

But researchers energetically protested that the new files would be incompatible with open-source software that has been developed by academics to work with the company's microarrays. Such software is free for everyone to use.

On 2 July, Affymetrix said that it would change course to ensure that its upgraded technology would not render the free software obsolete.

Microarray chips are covered in thousands of strands of DNA, each corresponding to a known gene and marked with a fluorescent molecular tag. Researchers add a sample of biological material to the chip, and the DNA in the sample bonds to the sequences on the chip. The chip outputs its results - a record of which dots are glowing, and how brightly — as a computer file. At present, these files can be opened on almost any computer.

Affymetrix announced late last year that it would upgrade its microarrays to produce

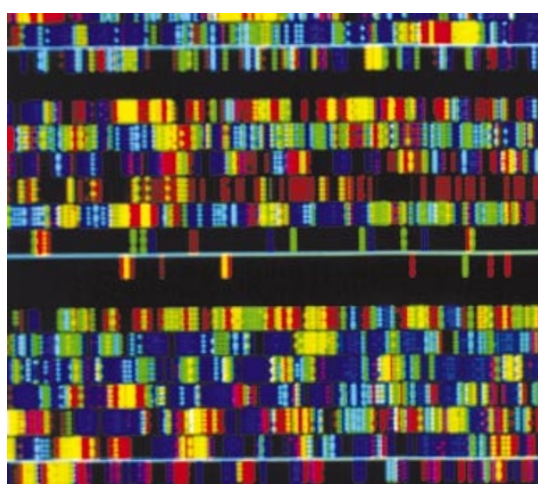

Chip panned: biologists prefer using open-source software to analyse their microarray data.

data as smaller files in a proprietary format. The change would have made it easier to modify formats in the future without disrupting the analysis software, says David Kulp, a bioinformaticist at the company.

But the move would have placed the microarray data files off-limits to the developers of open-source software. It would also have rendered useless many existing tools for interpreting the data, including a popular one called Bioconductor.

Many molecular biologists are happy with the simple file format produced by Bioconductor. "The file is readable by a human," says James MacDonald, who uses Bioconductor to analyse output from chips at the University of Michigan's microarray facility at Ann Arbor.
Researchers' worries were increased by the fact that US law now makes it difficult to write open-source software to interface with proprietary formats. On 27 June, 21 members of the group that develops Bioconductor announced that they would not develop software for a private file format.

"We wouldn't be willing to do anything that was marginally legal," says group member Robert Gentleman, a statistician at the Harvard School of Public Health. Researchers working on software in their spare time lack the resources to deal with proprietary file formats, he adds.

Besides the inconvenience to researchers forced to use new software, losing the efforts of a large group working out how best to analyse microarray data would have damaged the field as a whole, Gentleman argues. "The technology isn't mature yet. We need a lot of clever people working on these problems," he says.

Last week, after conferring with the Bioconductor team, Affymetrix announced that its new compressed format will be made public. "We don't have any trouble with this," says Kulp. "Clearly, some developers prefer to write their own file readers, which is more work on their part, but has advantages to open-source software distribution."

"I think that science won," says Gentleman. But he doubts that the issue will go away: "The clash between open source and commercialization will probably be a constant minefield for both sides."

\section{UK shock tactics repel animal-rights activists in Japan}

\section{David Cyranoski, Tokyo}

British animal-rights activists have pledged to export their fight to Japan. But animalrights groups in Tokyo, after a brief dalliance with the outsiders, are recoiling from their aggressive tactics, which they say could backfire there.

Stop Huntingdon Animal Cruelty (SHAC), an animal-rights group based in Worcestershire, UK, said earlier this year that it planned to target Japanese academic and industrial researchers, saying that they make up one-fifth of the customer base of controversial UK animal-testing company Huntingdon Life Sciences. SHAC has already demonstrated against the European branches of many Japanese companies.

When SHAC member Dawn Hurst arrived in Tokyo in April to demonstrate at a pharmaceutical trade show, she was charged with the theft last year of a dog that was being used in experiments at Juntendo University. But after two directors of the
Tokyo-based Animal Rights Center (ARC) were also arrested in connection with the theft last week, the group has backed away fast from its association with SHAC.

Susumu Kawaguchi and Yukari Sugisaka of the ARC claim that they were keeping the dog at their shelter after it was given to them as a stray by Hurst, who has reportedly admitted stealing it. ARC representatives helped Hurst to find lodgings when she came to Japan but say that they were unaware of any illegal activity.

The ARC seeks to draw attention to animal cruelty in Japan. "Japanese consciousness of this problem is very thin," admits Chihiro Okada, another director of ARC. But Japanese sensibilities frown on the use of illegal means in the pursuit of political ends. "Given the Japanese character, radical activity would only alienate people," says Okada.

The ARC and larger animal-rights groups such as the Japan Antivivisection
Association (JAVA) say that they do not support SHAC's activities.

Hurst has also been charged with the theft of research materials relating to animal experiments in several Japanese laboratories. In August 2001, for example, she entered Osaka University's pharmacology department by posing as a graduate student from a British university, according to Osaka neuroscientist Masaya Tohyama. Hurst allegedly stole videos and photographs, which were later posted on SHAC's homepage.

Tohyama says that SHAC's tactics had some initial success, but that the laboratory was able to explain what it was doing and why. "The only thing that changed was that we became more wary of outsiders trying to get into the labs," he says.

But SHAC spokesman Greg Avery says that the group's activities have influenced the research of some Japanese companies, and that it plans to escalate operations against Japanese researchers. 